\title{
Felicidade e Consumo em Tempos de Redes Sociais: uma Análise do Compartilhamento de Postagens de Experiências
}

\section{Happiness and Consumption in Social Media Times: an Analysis of Sharing Experience Posts}

\author{
Vanessa Saldanha Pinheiro \\ Universidade Estadual do Ceará - UECE - Brasil \\ vanessasp10@gmail.com
} ORCID: 0000-0002-4722-8999

Ana Augusta Ferreira de Freitas

Universidade Estadual do Ceará - UECE - Brasil

ana.freitas@uece.br

ORCID: 0000-0002-2741-6968

Felipe Gerhard

Universidade Estadual do Ceará - UECE - Brasil gerhard.sousa@aluno.uece.br ORCID: 0000-0002-1117-5960

Submetido em 04/10/2020; Aprovado em 01/12/2020.

\begin{abstract}
Resumo
Objetivo: Este trabalho tem como objetivo compreender o reconsumo dentro do contexto da felicidade proporcionada pela repercussão social positiva de experiências publicadas nas redes sociais. Método: Uma pesquisa qualitativa foi conduzida através de entrevistas semiestruturadas com 17 usuários ativos do Facebook convidados a dialogar enquanto navegavam em suas contas pessoais. Como forma de apreciação dos dados, utilizou-se a análise temática, que gerou três unidades temáticas, cinco temas, oito subtemas e quarenta códigos. Resultados: Os discursos mostraram que, de fato, elogios e retorno positivo nas fotos aumentam a felicidade e são grandes propulsores motivacionais ao reconsumo, assim como revelam que essa ação está imersa em questões sociopsicológicas, como a busca pelo reconhecimento e prestígio. Evidencia-se, assim, que o uso das redes sociais está diretamente atrelado às relações interpessoais, à felicidade e ao consumo. Contribuições: 0 artigo visa a contribuir teórica e empiricamente com o conhecimento produzido sobre o comportamento do consumidor nas redes sociais e a psicologia do consumidor, além de fornecer, tacitamente, diretrizes às marcas, que desejam entender melhor o público, para desenvolver seu gerenciamento de marketing, de produto, de serviço e/ou de campanhas publicitárias.
\end{abstract}

Palavras-chave: Felicidade; Experiências; Consumo; Reconsumo; Facebook

\section{Abstract}

Objective: This work aims to understand reconsumption within the context of happiness provided by the positive social repercussion of experiences published on social networks. Method: A qualitative research was conducted through semi-structured interviews with 17 active Facebook users invited to talk while browsing their personal accounts. Thematic analysis was used as a way of assessing the data, which generated three thematic units, five themes, eight subthemes and forty codes. Results: The speeches showed that, in fact, praise and positive feedback in the photos increase happiness and are great motivational drivers for reconsumption, as well as revealing that this action is immersed in sociopsychological issues, such as the search for recognition and prestige. Thus, it is evident that the use of social networks is directly linked to interpersonal relationships, happiness and consumption. Contributions: The article aims to contribute theoretically and empirically with the knowledge produced about consumer behavior on social networks and consumer psychology, in addition to providing tacitly 
guidelines to brands that wish to better understand the public to develop their marketing, product and service management and/or advertising campaigns.

Keywords: Happiness; Experiences; Consumption; Reconsumption; Facebook

\section{Introdução}

As redes sociais se tornaram, nos últimos anos, um dos principais meios de comunicação. Seja para facilitar as relações sociais, seja para fins de engajamento social, o ponto central é a interação entre os amigos e a obtenção de informações que, em geral, vêm em formato de fotos, vídeos e textos (Ellison \& Boyd, 2013). A expansão no uso dessas ferramentas online estimula e influencia comportamentos individuais ou grupais em múltiplos contextos, inclusive no ato de consumo (Barasch, Diehl \& Zauberman, 2018). Assim, entre outras finalidades, essas comunidades virtuais oferecem aos seus usuários a oportunidade de compartilhar as posses que os cercam e as experiências que os definem (Belk, 2013).

Partindo-se da teoria de que as experiências constroem a vida das pessoas e as definem como sujeitos (Van Boven \& Gilovich, 2003; Carter \& Gilovich, 2012), a exposição desse tipo de consumo fazse presente não somente no ambiente físico, mas também no virtual. Isto se deve, provavelmente, ao fato de que as pessoas se sentem mais felizes ao compartilharem suas experiências do que suas posses (Van Boven, Campbell \& Gilovich, 2010; Caprariello \& Reis, 2012; Moore, 2014). Compartilhar momentos pessoais com aqueles que não estavam presentes no instante da experiência vivifica o humor dos que a vivenciaram, assim como amplia o significado da situação na qual estiveram (Reis, Smith, Carmichael \& Caprariello, 2010), contribuindo, dessa forma, com a felicidade que os indivíduos obtêm de suas relações interpessoais (Barasch et al., 2018).

Apesar dos eventuais benefícios provenientes desse compartilhamento, há um viés negativo relacionado à exposição em redes sociais (Caprariello \& Reis, 2012; Barasch et al., 2018). Aqueles que tiram fotos com o objetivo precípuo de compartilhá-las nas mídias têm o prazer proveniente das experiências reduzido, devido à diminuição do seu envolvimento pessoal durante a realização da vivência. Isto ocorre porque os indivíduos se preocupam, de forma intensa, com a imagem que estão transmitindo a terceiros e com a repercussão social decorrente desta (Barasch et al., 2018).

Gilovich e Gallo (2020), por meio de uma revisão dos estudos mais relevantes sobre compras materiais e experienciais, destacam a influência, positiva ou negativa, do compartilhamento de experiências online/offline na formação psicológica do indivíduo, bem como a maneira como esse compartilhamento interfere na felicidade, no prazer e no bem-estar. Todavia, não há evidências de pesquisas nesse campo que busquem averiguar a atuação de tal dinâmica para o consumo, isto é, de que maneira os benefícios e os malefícios do compartilhamento de experiências podem atuar não somente no âmbito sociopsicológico do sujeito, mas também no seu comportamento de consumo reiterado da mesma experiência.

Portanto, o objetivo do presente estudo é compreender o reconsumo dentro do contexto da felicidade proporcionada pela repercussão social positiva de experiências publicadas nas redes sociais. Para alcançá-lo, uma pesquisa qualitativa foi realizada por meio de entrevistas semiestruturadas com usuários ativos do Facebook, utilizando-se a técnica autodriving (Pugh, 2010) e a análise temática (Brawn \& Clarke, 2006) para apreciação dos discursos. Os resultados apontam que a repercussão social positiva nas publicações potencializa a felicidade e estimula o reconsumo, demonstrando que a dinâmica das redes está imersa em aspectos interpessoais, emocionais e psicológicos. Portanto, além desta introdução, este estudo divide-se em quatro seções. No referencial teórico, são apresentados os conceitos centrais sobre o tema de estudo. Na seção de método, tem-se o processo de pesquisa para o alcance dos objetivos traçados. Em seguida, os resultados são discutidos com base no arcabouço teórico emerso da literatura. Por último, as considerações finais são relatadas.

\section{Referencial teórico}

A função precípua das redes sociais é promover a interação e a comunicação entre pessoas em um ambiente virtual. Nele, as múltiplas ferramentas conferem um layout atrativo para que seus usos se tornem um exercício habitual. A exemplo do Facebook, os próprios usuários produzem o conteúdo do site/aplicativo no instante em que publicam fotos, vídeos e textos. Por conseguinte, é notável a presença de postagens que refletem o comportamento de consumo, como o compartilhamento de fotos de bens adquiridos e das experiências vividas (Ellison \& Boyd, 2013). As compras de bens materiais são aquelas que almejam a obtenção da posse e da propriedade de objetos por um período prolongado; ao passo que 
as compras experienciais são intangíveis, variáveis e têm a finalidade de vivenciar uma situação (Carter \& Gilovich, 2012).

Convém ressaltar que a literatura também faz uma distinção entre o que se entende por consumo de experiência e experiência de consumo, demonstrando que esses termos são mais do que um mero jogo de palavras. Para Pereira, Siciliano e Rocha (2015), a experiência de consumo nada mais é que toda e qualquer compra corriqueira caracterizada pela simples troca entre consumidor e fornecedor, ou seja, é a prática de consumir no seu sentido mais absoluto. Enquanto isso, o consumo de experiência diz respeito à imersão do indivíduo na situação do consumo. É o envolvimento emocional, sentimental e psicológico do sujeito com a experiência, a qual pode despertar sentidos distintos em pessoas diferentes graças aos seus múltiplos significados (Pereira et al., 2015).

O consumo de experiência, que aproxima a prática do consumo ao âmbito mais subjetivo e intangível do ato, remete muito ao que será exposto a seguir, no que se refere a como o consumo experiencial está intimamente ligado às questões emocionais, em especial à felicidade - considerada uma emoção primária (Gilovich \& Gallo, 2020; Gilovich, Kumar \& Jampol, 2014; Carter \& Gilovich, 2012; Caprariello \& Reis, 2012). Tal concepção difere de outra temática estudada por pesquisadores da área de comportamento do consumidor, que é a experiência do cliente. Segundo Becker e Jaakkola (2020) e Keiningham, Aksoy, Bruce, Cadet, Clennell, Hodgkinson e Kearney (2020), a experiência do cliente é definida como respostas não deliberadas e espontâneas a estímulos específicos, resultantes das interações entre o consumidor e a empresa por meio das suas ofertas e serviços.

Isto posto, no que concerne ao ato de vivenciar uma experiência, Bhatacharjee e Molginer (2014) o classificam em duas categorias: ordinário e extraordinário. As experiências ordinárias correspondem às situações que ocorrem dentro da esfera cotidiana, repetindo-se rotineiramente e tendo como notória característica a habitualidade, enquanto as extraordinárias representam eventos raros e pouco frequentes, incomuns no dia a dia e excepcionais na vida dos indivíduos que as vivenciam.

Quadro 1 - Por que experiências trazem mais felicidade do que posses?

\begin{tabular}{|c|c|c|}
\hline Justificativa & Teoria & Referência \\
\hline $\begin{array}{l}\text { Arrependi- } \\
\text { mento }\end{array}$ & $\begin{array}{l}\text { Os consumidores se arrependem mais por terem adquirido } \\
\text { um bem, graças à sua natureza tangível, do que por não terem } \\
\text { adquirido uma experiência, por sua natureza intangível. }\end{array}$ & Gilovich et al. (2014) \\
\hline Adaptação & $\begin{array}{l}\text { O fato de que os bens ficarem a maior parte do tempo na } \\
\text { posse de um indivíduo, com o tempo, o desejo pelo bem se } \\
\text { perde, devido à adaptação. }\end{array}$ & $\begin{array}{c}\text { Carter e Gilovich (2012) e Gilovich, Ku- } \\
\text { mar e Jampol (2014) }\end{array}$ \\
\hline Ambiguidade & $\begin{array}{l}\text { Uma maior possibilidade de conferir significados diversos às } \\
\text { experiências do que às posses, uma vez que a reflexão sobre } \\
\text { uma situação, em muitos casos, leva os indivíduos a olharem } \\
\text { o lado positivo, mesmo que não tenha saído conforme o pla- } \\
\text { nejado. Isso não é comum com posses. }\end{array}$ & Carter e Gilovich (2012) \\
\hline $\begin{array}{l}\text { Interação So- } \\
\text { cial }\end{array}$ & $\begin{array}{l}\text { O compartilhamento de experiências com outras pessoas, em } \\
\text { contraste a situações solitárias ou aquisições de objetos ma- } \\
\text { teriais, é veículo substancial para a felicidade. }\end{array}$ & $\begin{array}{l}\text { Van Boven e Gilovich (2003); Van Bo- } \\
\text { ven et al. (2010); Caprariello e Reis } \\
\text { (2010); Gilovich et al. (2014) e Gilovich } \\
\text { e Gallo (2020) }\end{array}$ \\
\hline Identidade/Self & $\begin{array}{l}\text { Os indivíduos são a soma de suas experiências, não de suas } \\
\text { posses. Assim, estão mais inclinados a se sentirem felizes por } \\
\text { algo que compõe o seu eu. }\end{array}$ & $\begin{array}{l}\text { Gilovich et al. (2014); Bronner e Hoog } \\
\text { (2018) e Gilovich e Gallo (2020) }\end{array}$ \\
\hline $\begin{array}{l}\text { Comparação } \\
\text { Social }\end{array}$ & $\begin{array}{c}\text { O fato de as experiências estarem mais associadas à identi- } \\
\text { dade dos sujeitos, estas estão menos propensas a gerar com- } \\
\text { paração social do que as posses, o que influencia diretamente } \\
\text { na felicidade e no bem-estar. }\end{array}$ & $\begin{array}{c}\text { Gilovich et al. (2014); e Gilovich e Gallo } \\
(2020)\end{array}$ \\
\hline
\end{tabular}

Fonte: elaborado pelos autores.

Em consonância com Bhatacharjee e Mogilner (2014), alguns estudos apontam que as experiências são capazes de prover uma felicidade mais duradoura e de maior intensidade, comparada àquela depreendida da posse de bens materiais (e.g. Van Boven \& Gilovich, 2003; Carter \& Gilovich, 2012; Gilovich, Kumar \& Jampol, 2014; Bronner \& Hoog, 2018). Em outras palavras, vivenciar experiências torna as pessoas mais felizes do que obter posses. Seguindo esta linha de raciocínio, a literatura mune-se de razões que justificam a premissa acima destacada. Dentre elas, podem ser elencadas: arrependimento da compra de bens materiais, habituação/adaptação aos bens materiais, ambiguidade, interação social, 
identidade/self e comparação social. O Quadro 1 apresenta as razões apontadas na literatura.

Cabe destacar que, apesar do crescente interesse da academia por estudos voltados à felicidade devido à ampla possibilidade de discussão, não há um consenso definitivo sobre o seu conceito. Para a Economia, o conceito de felicidade está atrelado ao bem-estar subjetivo (Torres, Pereira \& Santos, 2012). De maneira complementar, este campo de pesquisa também associa a felicidade à obtenção de bens materiais, isto é, quanto mais situações de consumo material o indivíduo tiver, mais feliz ele se sentirá (Caselani, 2004).

Já para a Psicologia, a felicidade, além de ser considerada como uma emoção básica ou primária por diversos autores clássicos (e.g. Izard, 1971; Tomkins, 1984; Fridja, 1986), também é vista como uma condição momentânea, passageira, um ideal a ser perseguido pelo sujeito, especialmente quando há a volta ao estado de insatisfação (Perez, 2004). Em oposição ao campo da Economia, pesquisadores da área de Psicologia entendem que o consumo de experiências provoca mais felicidade do que bens, pois, dentre outros motivos, conforme já explanado, o compartilhamento de experiências promove melhores conexões e relações interpessoais (Ver Quadro 1).

No que concerne à área de Mídias Sociais, alguns estudos já trataram dos efeitos causados pelo compartilhamento de experiências, através de fotos, nas redes sociais. Esse exercício de exposição da intimidade, outrora limitada a um círculo pessoal mais restrito, ganha novas dimensões e consequências com os emergentes recursos audiovisuais e interativos (Sibilia, 2015). Moore (2014) sugere que a autoestima dos indivíduos pode ser afetada quando estes compartilham informação sobre compras que podem estigmatizá-los, a exemplo dos bens materiais que, por vezes, transmitem uma estereotipada imagem consumista, fútil e superficial.

Por outro lado, as experiências refletem imagens bem mais atraentes aos que aspiram a uma velada exposição dos seus hábitos de consumo. Ainda que o conceito de compra material seja diferente do de compra materialista, os bens são estigmatizados nesse sentido, e, em razão do receio de ser alvo de julgamentos, a autoestima daqueles que os compartilham pode diminuir (Van Boven et al., 2010; Caprariello \& Reis, 2012; Moore, 2014). Na esteira dessa discussão, Zhang, Li, Gu e Luo (2020) e Duan e Dholakia (2018) afirmam que, no âmbito das redes sociais, os usuários preferem compartilhar experiências justamente por conta de uma aprovação ou repercussão social positiva - gerada pelas curtidas e comentários - que não seria conquistada da mesma forma, caso fossem bens materiais.

Para Barash, Diehl e Zauberman (2018), tirar fotos com o objetivo de compartilhar com outros aumenta mais a felicidade proveniente da experiência vivida do que quando se tem apenas o propósito de guardá-las para a memória, especialmente quando a repercussão social é positiva. Caprariello e Reis (2012) também afirmam que o compartilhamento de experiências com terceiros pode ser benéfico ao ponto de levar os indivíduos a valorizarem mais as experiências do que as posses.

Apesar dos ganhos decorrentes das interações entre sujeito, publicação e amigos, há que se falar dos efeitos negativos oriundos dessa dinâmica. Ansiedade, pressão e preocupação são sensações experimentadas por aqueles que vivenciam uma experiência e tiram fotos com o fim de compartilhá-las com amigos (Barasch et al., 2018). Mostrar-se bem, expor-se de modo favorável e passar imagens positivas com a finalidade de se sentir acolhido pelo meio social são a tônica subjacente às publicações online (Jain, Belk, Ambika \& Pathak-Shelat, 2020), e isso pode acabar gerando certo desconforto quanto à expectativa de retorno dos amigos (Belk, Ger \& Askeergard, 2003).

No entanto, a despeito desses sentimentos nocivos ao próprio self, os indivíduos continuam a utilizar as redes sociais e persistem em publicações e exposições de suas vidas, visto que a busca por uma repercussão positiva, traduzida por reconhecimento ou destaque, parece se sobrepor às desvantagens inerentes ao jogo de postagens. Tal dinâmica pode ser entendida como um agradável desconforto (Belk, et al., 2003). Esse conceito, em um primeiro momento, foi tratado por Campbell (1987), no âmbito do desejo do consumidor, que apresentou um modelo em forma de ciclo vicioso: antecipação, consumação, desapontamento e desejo renovado por outro objeto. Apesar de não ter como foco o ambiente virtual, esse modelo pode ser aplicado, em sentido figurado, para explicar a dinâmica dos usuários nas redes sociais.

Ademais, o compartilhamento de experiências em ambientes virtuais também pode provocar outros efeitos. Consequências sociopsicológicas como repercussões na felicidade e nas relações interpessoais são apenas a ponta do iceberg, visto que numerosas são as particularidades e subjetividades de cada indivíduo. Acredita-se que tais implicações também guardam relações intrínsecas com o comportamento de consumo, já que os próprios objetos das publicações, bens e experiências, são resultantes de 
atos de compras.

0 questionamento que permeia tal estudo refere-se justamente ao modo como essas características (felicidade, interação social e repercussão social positiva), em conjunto, podem confluir para o consumo (ou reconsumo). A ação preliminar à postagem é o consumo, o qual posteriormente conduz a outras interações sociais por meio das publicações. A redução ou a intensificação da felicidade é uma das consequências. No entanto, pode-se esperar que exista outro resultado em potencial, o reconsumo, à medida que uma repercussão social positiva possa funcionar como um reforço para viver novamente aquela experiência de consumo. Esse reconsumo, que ocorre de forma voluntária, pode ter o intuito de adquirir novas perspectivas (Russel \& Levy, 2012), mas pondera-se, aqui, sobre a possibilidade de este ter sido motivado pelas interações interpessoais promovidas nas redes sociais.

\section{Método}

Para atingir o objetivo do estudo, utilizou-se uma abordagem de pesquisa qualitativa. Optou-se por esta abordagem, pois a pesquisa não pretende testar uma teoria específica, nem seguir uma rota dedutiva, como é comum em pesquisa de cunho quantitativo. Este estudo, portanto, pretende explorar o fenômeno através da compreensão e interpretação de experiências vividas pelos sujeitos da pesquisa. Para os propósitos específicos do estudo, as entrevistas individuais semiestruturadas foram selecionadas como método de coleta de dados (Krueger, 1998).

A entrevista, portanto, seguiu um fluxo planejado. Primeiramente, se apresentou e explicou, aos sujeitos da pesquisa, o objetivo do diálogo. A introdução da entrevista foi propositadamente muito geral, a fim de não influenciar os participantes a respostas previamente pensadas. Inspirado no estudo de Fortis (2015), após a fase introdutória da entrevista, os participantes foram convidados a recordar sua última experiência vivida e compartilhada no Facebook, descrevendo o destino, a duração, a natureza da experiência, entre outros detalhes. Isso foi feito com o objetivo de capacitá-los a lembrar, em termos de comportamentos, opiniões e sentimentos, o que ocorreu antes, durante e depois das postagens de suas experiências pessoais e prepará-los para a entrevista propriamente dita.

Posteriormente, os participantes foram solicitados a acessar sua conta pessoal do Facebook. A metodologia de usar a própria conta pessoal do entrevistado foi uma estratégia inspirada em estudiosos de mídias sociais. Para Pugh (2010), a técnica autodriving, que consiste em navegar no próprio perfil durante a entrevista, facilita sobremaneira a recordação de experiências, pois os indivíduos têm a possibilidade de trazer para o ambiente da conversa suas fotos e vídeos pessoais. As motivações para escolha e compartilhamento de experiências, a interação em rede social, a repercussão social (curtidas, comentários e compartilhamentos) com os amigos, os sentimentos pré e pós-postagem e o comportamento de consumo estiveram presentes nos questionamentos e nos relatos.

A construção do corpus seguiu um critério de seleção intencional dos participantes da pesquisa. Segundo Bryman (2008), na seleção intencional, recrutam-se participantes relevantes para as entrevistas. Esta pesquisa elencou dois critérios para a escolha dos participantes. 0 primeiro critério delimitou que os entrevistados fossem usuários com conta ativa há, pelo menos, três anos. 0 segundo delineou que os participantes tivessem entre 15 e 34 anos, pois, conforme o relatório Statista (2019), esse é o grupo formado pela maior parte dos usuários de internet e redes sociais no Brasil. Além disso, o corpus foi composto por estudantes universitários. Segundo Fortis (2015), os estudantes universitários são considerados informantes ricos para um estudo que envolve mídias sociais, pois eles tendem a se sentir confortáveis com todos os tipos de formatos emergentes da internet e a ser engajados com estes.

0 corpus de pesquisa foi composto por 17 pessoas, sendo 11 do sexo feminino e 6 do sexo masculino. As entrevistas aconteceram do dia 5 ao dia 12 de junho de 2017, foram conduzidas por um dos pesquisadores deste artigo e duraram entre quarenta minutos a uma hora e meia cada, dependendo da extensão da interação e do grau de extroversão do participante. A quantidade de respondentes foi estabelecida por meio do grau de saturação das respostas (Morgan, 1996). Ademais, as entrevistas aconteceram em um laboratório de pesquisa de uma universidade do Nordeste do Brasil. Como incentivo à participação, os entrevistados receberam certificados de horas de atividades complementares, que são exigidos ao final do curso para a colação de grau. Entre outras providências que foram seguidas, conforme regulamentação do Conselho de Ética para pesquisas com seres humanos, os participantes assinaram um formulário de consentimento. Concordaram, por livre e espontânea vontade, em realizar a entrevista e anuíram à gravação de áudios, bem como ao posterior uso das citações, em anonimato, na 
apresentação dos resultados do estudo.

Como forma de apreciação dos dados, utilizou-se a análise temática de Braun e Clarke (2006), com base nos transcritos dos áudios gravados em cada entrevista. Vista como um método útil para identificar, analisar e relatar padrões (temas) que refletem todo o conjunto de dados, a análise temática se mostrou adequada para esse estudo (Souza, 2019). Isto posto, optou-se pela combinação da análise temática teórica, cujo objetivo é encontrar padrões ou temas semânticos que possuam fundamentação na literatura, com a análise temática indutiva, que se propõe a deixar o pesquisador mais livre no momento de classificação e definição de temas latentes (Braun \& Clarke, 2017).

Ao todo, geraram-se três unidades temáticas, cinco temas, oito subtemas e quarenta códigos. Para chegar a esse resultado, o trajeto metodológico de análise seguiu o processo detalhado por Braun e Clarke (2006), que não é linear, mas recursivo entre seis fases que eles destacam como familiarização com os dados, geração dos códigos iniciais, pesquisa temática, revisão de temas, definição e nomenclatura dos temas, e produção do relatório.

\section{Apresentação e discussão dos resultados}

Com base no processamento de análise temática apresentado por Braun e Clarke (2006), foram identificadas três unidades temáticas que funcionam como uma espécie de "guarda-chuva" para os temas, subtemas e códigos que lhes são correlacionados. Estas unidades temáticas foram nomeadas de inputs, processamento e outputs. A despeito de estas classificações impelirem um ideal mecânico e engessado, a dinâmica sociopsicológica das redes sociais é fluida, cíclica e opera em direções diversas, conforme será apresentado nas discussões dos resultados. Isto posto, para proporcionar uma apresentação um pouco mais didática das análises, as classificações das unidades temáticas operam apenas como um pequeno recorte do fluxo contínuo e movimentado das redes.

Com a observação conjunta de todas as entrevistas, verificou-se que alguns temas funcionavam como "entradas" ou início da dinâmica das redes, outros poderiam ser entendidos como "ação" ou "produção" e outros como "saídas" ou resultados do processamento anterior. Assim sendo, vislumbraramse estímulos, ferramentas e o próprio consumo como inputs, através de postagens, de fotos de bens e das experiências e da própria função da mídia, enquanto o movimento das redes, por meio das métricas de reconhecimento e do gerenciamento de autoimagem, pareceu atuar como mecanismo de processamento das "entradas". Finalmente, entendeu-se o reconsumo como sendo uma "saída" ou "output" evidente nos discursos dos participantes, sendo este decursivo de uma repercussão positiva dos seguidores/amigos e da felicidade decorrente.

Quadro 2 - Resultado da análise temática

\begin{tabular}{|c|c|c|c|c|c|c|c|c|}
\hline \multirow{2}{*}{\begin{tabular}{|c|}
$\begin{array}{r}\text { Unidades } \\
\text { temáticas }\end{array}$ \\
Temas \\
Subtemas \\
\end{tabular}} & \multirow{2}{*}{\multicolumn{2}{|c|}{$\begin{array}{ll} & \\
\text { Estímulos } & \text { Ferramentas } \\
\end{array}$}} & uts & & \multicolumn{2}{|c|}{ Processamento } & \multicolumn{2}{|c|}{ Outputs } \\
\hline & & & \multicolumn{2}{|c|}{ Consumo } & \multicolumn{2}{|c|}{ Movimento das redes } & \multicolumn{2}{|c|}{ Reconsumo } \\
\hline Subtemas & $\begin{array}{c}\text { Motivações para } \\
\text { postar }\end{array}$ & $\begin{array}{c}\text { Elementos } \\
\text { sociomateriais }\end{array}$ & Bens & Experiências & $\begin{array}{l}\text { Métricas de } \\
\text { reconhecimento }\end{array}$ & $\begin{array}{c}\text { Gerenciamento } \\
\text { de } \\
\text { autoimagem }\end{array}$ & $\begin{array}{l}\text { Retorno } \\
\text { positivo }\end{array}$ & Felicidade \\
\hline Códigos & $\begin{array}{c}\text { Exibição } \\
\text { Exposição } \\
\text { Competitividade } \\
\text { Aspectos } \\
\text { interpessoais } \\
\text { Laços sociais } \\
\text { Grupos sociais } \\
\text { Componente } \\
\text { social } \\
\text { Conexões } \\
\text { sociais }\end{array}$ & $\begin{array}{c}\text { Postagens } \\
\text { Fotos } \\
\text { Mídia }\end{array}$ & $\begin{array}{l}\text { Consumo } \\
\text { massificado } \\
\text { Futilidade }\end{array}$ & $\begin{array}{l}\text { Consumo } \\
\text { velado } \\
\text { Inclinações } \\
\text { materialistas } \\
\text { Experiências } \\
\text { extraordinárias }\end{array}$ & $\begin{array}{c}\text { Likes } \\
\text { Curtidas } \\
\text { Comentários }\end{array}$ & $\begin{array}{l}\text { Expectativas } \\
\text { Ansiedade } \\
\text { Agradável } \\
\text { desconforto } \\
\text { Comparações } \\
\text { sociais } \\
\text { Construção de } \\
\text { identidade }\end{array}$ & $\begin{array}{c}\text { Reconhecimento } \\
\text { Fortalecimento } \\
\text { da autoestima } \\
\text { Status } \\
\text { Prestigio } \\
\text { Padrão } \\
\text { Bem-estar } \\
\text { Vaidade } \\
\text { Recompensa }\end{array}$ & $\begin{array}{c}\text { Emoção } \\
\text { Inconsciente } \\
\text { Subjetividade } \\
\text { Sociopsicológico } \\
\text { Equilibrio } \\
\text { psicológico }\end{array}$ \\
\hline
\end{tabular}

Fonte: elaborado pelos autores.

No que concerne à palavra "evidente" utilizada no parágrafo anterior, assim como preceituado por Braun e Clarke (2017), não somente o tema "reconsumo" foi frequente nas falas dos entrevistados, mas também em todos os outros temas, bem como nos subtemas e em seus respectivos códigos de análise. Para tal, buscou-se a observação de padrões nos relatos e de respostas que fossem comuns à maioria. A análise temática, portanto, prezou pela repetição nos discursos e elencou palavras que representassem as falas mais recorrentes, para que estas pudessem compor o esquema temático que pode ser visto no 
Quadro 2. A dinâmica desses temas será discutida de maneira argumentativa e reflexiva a seguir.

0 processo que impulsiona o engajamento em redes sociais guarda controvérsias constituintes. Ao analisar as falas dos respondentes, observamos que, apesar de expressarem livremente as suas subjetividades, há um forte componente social orientando o comportamento individual - o que caracteriza as ações nas redes sociais como um contínuo duelar entre a liberdade e a obediência.

De fato, estar em rede pressupõe estar sujeito a inflexões sociais. Entretanto, elas não apenas alcançam a superfície do comportamento, adentrando em camadas mais profundas que atingem os processos de formação das suas próprias subjetividades. No centro desse processo de formação sociopsicológica, encontram-se a busca e a exibição de experiências, em especial as extraordinárias, como vetor da construção de identidades e estreitamento de laços sociais (Bhatacharjee \& Mogilner, 2014). Assim como apontado na literatura (Barash, Diehl \& Zauberman, 2018; Caprariello \& Reis, 2012), alguns entrevistados indicaram uma maior felicidade ao compartilhar especificamente experiências.

"Não chego a dizer 'ah, comprei tal coisa'. Eu mantenho o máximo de discrição possível na hora de postar. Mas, tipo, viagens eu acabo postando ou quando vou em algum canto. Já postei fotos em shows e restaurantes também."

"Eu não gosto de compartilhar coisas de bens, sabe? Eu sou uma pessoa muito mais de experiências do que bens materiais, sabe? Tem amigos meus que compartilham esse tipo de coisa, eu olho, visualizo, comento, mas não é algo que eu sinto vontade de postar, não me sinto feliz. Me sinto mais feliz postando experiências."

As experiências mantêm um forte antagonismo com a posse de bens nas redes. Enquanto os bens proporcionam um consumo massificado, as experiências são permeadas de subjetividades: um artifício sutil para dinamizar o jogo de comparações e prestígio (Bronner \& Hoog, 2018). Apesar de eventualmente similares, elas jamais poderão ser uniformemente comparadas. Por outro lado, os bens estão relacionados à vaidade e à futilidade (Moore, 2014), o que prejudica, ao invés de reforçar, a manutenção dos laços sociais e a própria construção de um eu ideal (Zhang et al., 2020).

"[...] Eu particularmente não gosto de tá mostrando o que eu tenho ou deixo de ter. Às vezes eu acho um pouco fútil assim, você tá mostrando que 'ah, eu tenho um carro, eu tenho uma moto', eu não acho legal."

"Experiências são mais enriquecedoras do que bens. Porque bens ficam, já experiências são únicas e são suas, entende? Bens qualquer outra pessoa pode levar ou, até mesmo, se perdem, mas experiências não."

A predileção por experiências, entretanto, não isenta os respondentes de apresentarem inclinações materialistas (Zhang et al., 2020). De modo reiterado, são comentadas não apenas situações que envolvam propriamente o ato de consumir, como restaurantes, festas e viagens, mas contextos no qual o indivíduo estava inserido, como um veleiro ou fotos em shopping centers. A aparência de destaque ante os outros, por meio de postagens que demonstrem ócio e indiferença à utilidade, é a tônica das experiências comentadas pelos entrevistados.

Independentemente das particularidades presentes nas experiências vividas, elas estimulam a vontade de postar do usuário quando se caracterizam como objeto de bem-estar. De fato, sentir-se bem é um dos principais condicionantes para a postagem (Nicolao, Irwin \& Goodman, 2009; Carter \& Gilovich, 2010; Carter \& Gilovich, 2012; Caprariello \& Reis, 2012; Gilovich et al., 2014; Duan \& Dholakia, 2018).

"Sempre muito feliz. Pra eu postar eu tenho que tá num grau de felicidade muito alto que não cabe em mim e eu preciso compartilhar com outras pessoas."

"É uma sensação de felicidade, de alguma forma. Pelo fato de eu tá compartilhando um momento importante pra mim com os meus amigos."

Estar bem, contudo, pode estar associado não apenas à experiência vivida, mas a uma expectativa em relação à postagem. Caso a situação tenha sido marcante, espera-se que provoque muitas curtidas e comentários, ou seja, uma repercussão social positiva. Como consequência de uma expectativa direcionada à reação de outrem, é inevitável que surjam preocupações inerentes à imprevisibilidade do seu 
comportamento. Essa é a causa da ansiedade pré-postagem (Barash, Diehl \& Zauberman, 2018). Em conjunto, bem-estar, expectativas e ansiedade constituem um fenômeno particularmente comum nas redes sociais, isto é, um agradável desconforto em compartilhar (enjoyable discomfort - cf. Belk et al., 2003).

\begin{abstract}
"Às vezes eu gosto assim muito de uma foto, aí eu fico muito ansiosa pra postar a foto, porque de certa forma, hoje em dia, as pessoas ficam "ah, não sei se vai dar tantas curtidas". É ansiedade de 'ah, o que as pessoas vão comentar nessa foto?"”.
\end{abstract}

"Fico ansiosa, não sei porquê, mas fico um pouco ansiosa, pra ver se vai rolar algum comentário, alguma coisa."

Apesar de os elementos supracitados serem constituídos por aspectos de ordem subjetiva, há uma forte influência de aspectos interpessoais neste processo. De fato, é essa relação que estimula a vontade de postar, de se expor continuamente nas redes sociais. A partir daí, a relação do usuário com a rede e a mídia social inicia-se de forma concreta, embora seja possível que ela não seja perdida de vista em momento algum. A mídia é o elemento sociomaterial que oportuniza essas relações e delineia o estilo de vida dos seus usuários. Obviamente, as postagens possuem nuances inumeráveis e cada indivíduo possui traços e características únicas, mas, em comum, há tanto um impulso por experiências quanto uma vontade de postá-las; sendo difícil indicar o que é causa ou efeito nessa relação.

De fato, as mídias sociais possibilitam a projeção do bem-estar e, muitas vezes, do equilíbrio psicológico em um sistema externo objetivo e aparentemente imparcial. Os likes e comentários caracterizam-se como métricas de reconhecimento e repercussão que, por sua própria natureza quantitativa, só poderiam ser "verdadeiras" (Barash, Diehl \& Zauberman, 2018). As redes sociais são capazes de objetificar, por meio de um conjunto simplificado de inputs, o jogo das relações sociais.

"[...] Você julga como foi o momento conforme as curtidas que vai recebendo. Se for várias curtidas, ou, se a pessoa que tá na foto não curtir, você acha que ela é esnobe e tal. [...] Eu acho que as pessoas acabam avaliando o momento pelo número de curtidas."

"Você se sente valorizada ou não. [...] Atualmente, eu acho que por ter conhecido mais pessoas, eu passei a receber mais curtidas. Isso acaba criando aquele sentimento de se sentir valorizada."

Como consequência, os usuários engajam-se em comparações que reforçam ideias, atitudes, comportamentos e, até mesmo, emoções. Mais do que estimular competições, tais comparações ajudam a aumentar a coesão do grupo e intensificar os laços sociais. É nesse cenário que as fotos surgem como um dos principais intermediadores das relações em redes. Considerada um hobbie para alguns respondentes, a foto é um importante componente sociomaterial que atesta e permite o compartilhamento de experiências.

Do mesmo modo, esses elementos visuais estimulam comentários, demarcam amizades e reforçam vínculos com pares que interessam (Jain et al., 2020). 0 fato de citarem experiências e pessoas, em vez de bens e posses, sugere uma necessidade mais profunda, relacionada a interações e conexões sociais. São mais comuns postagens no perfil pessoal em que estejam registradas as experiências extraordinárias vividas com amigos e pessoas próximas (Bhatacharjee \& Molginer, 2014).

\title{
"[...] Quando é um momento muito especial e que acontece raramente eu sempre posto."
}

"Não é todo local que eu saio que eu posto uma foto ou não é toda reunião de família que eu posto uma foto. É mais aquela que marcou de alguma forma. Quando é algo bem marcante mesmo, eu posto."

Os benefícios interpessoais ajudam a orientar os movimentos dos usuários nas redes, dando-lhes pistas dos seus próximos movimentos. A felicidade surge dessa relação interpessoal como estado mental que legitima e incentiva o jogo de postagem. É o indicador subjetivo que sinaliza a legitimidade do processo de engajamento na rede. Caso não houvesse um ganho nesse sentido, não haveria benefício imediato em fazê-lo.

"Se a foto tem muita curtida ou tem comentários que transmitam sentimentos, eu consigo ficar mais 
feliz. A minha felicidade perdura."

É a recompensa de todo um processo intersubjetivo, além de propiciar um (auto)reconhecimento e fortalecimento da autoestima. Sob essa perspectiva, a felicidade não se caracteriza como uma emoção exclusivamente subjetiva, relacionada apenas a processos pessoais de avaliação contextual. Guarda, ao contrário, um forte componente interpessoal, responsável por construir continuamente o próprio conceito de felicidade. Apesar de ser experienciada subjetivamente, a formação da felicidade considera uma série de disposições sociais apreendidas de forma inconsciente pelo indivíduo.

Além de a felicidade mostrar-se como a recompensa de todo esse processo sociopsicológico identificado na rede social, ela também funciona como uma orientação para outras práticas em segunda instância, como a do consumo/reconsumo - as quais podem ser entendidas como resultados objetivos extraídos das subjetividades emocionais mencionadas anteriormente. A repercussão social positiva influencia de tal modo a felicidade que, consciente ou inconscientemente, se torna uma espécie de fio condutor para que a experiência seja repetida (Russel \& Levy, 2012).

"Eu sei que se eu tenho um retorno positivo, eu fico com uma vontade de retornar a esse lugar, a ter uma outra experiência, apesar de muitas vezes não retornar da mesma forma, com as mesmas pessoas, mas mais cedo ou mais tarde eu vou retornar."

"Eu acho que isso é intrínseco realmente do ser humano, quando vocêfaz determinado ato e é reconhecido, isso faz com que você volte a fazer aquilo."

"[...] Eu acho que quando você curte (a foto), você tá dando valor pra aquilo, entendeu? Você acaba querendo viver de novo aquilo."

"Quando você recebe, geralmente, muita curtida em uma foto, você vai analisar por que aquela foto recebeu essa quantidade de curtida, aí você costuma seguir esse padrão pra receber esse tanto de curtidas que recebeu antes, entendeu? Então, influencia, com certeza."

"[...] O reconhecimento me fez, sei lá, ver que eu devo continuar nisso e participar de outras experiências como essa."

Nas duas últimas falas, percebe-se que, embora alguns entrevistados tenham mencionado uma vontade de reconsumir a mesma experiência, outros relataram, na verdade, uma busca por um padrão de consumo que gere mais curtidas. As expressões "analisar porque aquela foto recebeu essa quantidade de curtidas", "seguir esse padrão", "participar de outras experiências como essa" revelam um ato não propriamente de reconsumo da mesma experiência, mas reconsumo de experiências de um tipo "padrão" que possa lhes proporcionar a mesma quantidade de curtidas.

Em suma, a recorrente menção a experiências de consumo parece revelar a existência de um imaginário social comum. Sejam extraordinárias ou não, as experiências (de consumo) caracterizam-se como condutores importantes ao reconhecimento e status em relação aos pares. Não somente o reconsumo em si, como ato último de um processo cíclico, mas a busca por experiências também revela uma cultura de consumo generalizada, a qual, por meio da reprodução de hábitos, demonstra-se capaz de formar e manter laços sociais. E, mais do que isso, revela a premência do social (virtual) como pano de fundo do pessoal, uma vez que os usuários invariavelmente se submetem ao olhar do outro para completar o ciclo da felicidade. 0 mais nítido exemplo é a influência do contexto sobre o processo de formação da felicidade e a sua relação com o ciclo de reconsumo de experiências.

Assim, é necessário entender as pessoas não como indivíduos isolados, mas como um conjunto de relações. Apesar de muitas vezes não reconhecerem, as ações dos usuários estão interrelacionadas, causando ressonância e dissonâncias em diversas instâncias da rede. Esse processo marca o surgimento de pequenos desequilíbrios na rede, isto é, distâncias sociais entre usuários, capazes de provocar um contínuo interregno associado tanto à conquista de prestígio ou status quanto à busca de elementos ainda mais basilares, como reconhecimento e autoestima.

Para tal, seus usuários devem ser capazes de captar e reproduzir um discurso social que permite declinações infinitas - em um constante fluxo de submissão e subversão. Nesse processo, condicionamse a participar de um jogo de relações simbólicas que posiciona e direciona muitas de suas ações. Entretanto, mais do que se orientarem por uma lógica de grupo, como ocorre nos fenômenos de consumo 
convencionais, os usuários são orientados por uma lógica de rede: consideravelmente mais ampla e complexa em muitos aspectos. A Figura 1 apresenta e relaciona os conceitos discutidos.

Figura 1 - Dinâmica Sociopsicológica das Redes Sociais

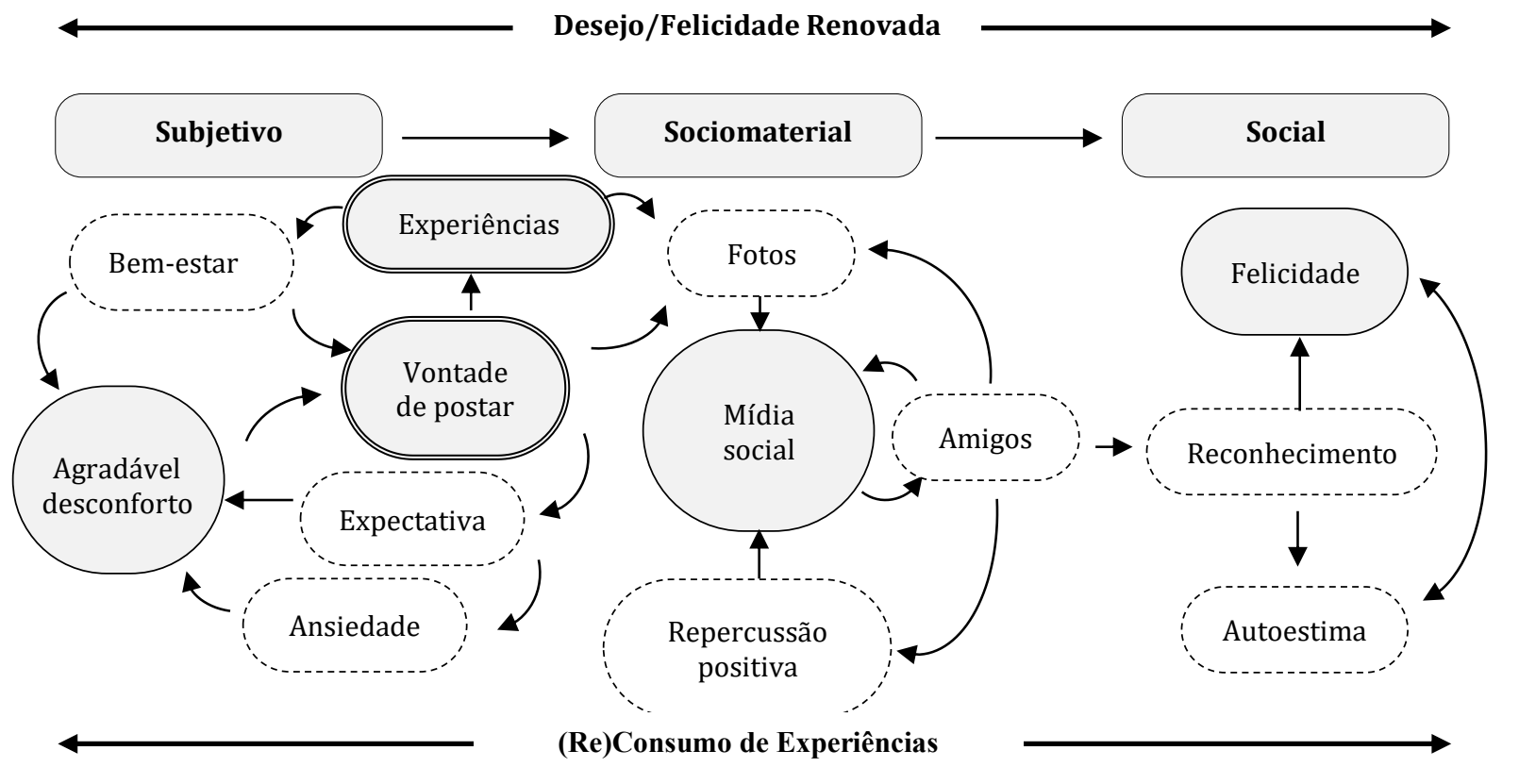

Fonte: elaborado pelos autores.

\section{Considerações finais}

Este artigo buscou compreender o reconsumo dentro do contexto da felicidade proporcionada pela repercussão social positiva de experiências publicadas nas mídias sociais. Para tanto, o estudo valeu-se de entrevistas individuais, semiestruturadas e mediadas pelo uso em tempo real dos perfis pessoais de cada participante. Em suma, a análise interpretativa dos relatos possibilitou o destaque de três direcionamentos para as considerações finais, a saber: o reconhecido alcance do objetivo proposto, as implicações teóricas e as contribuições gerenciais. Inicialmente, cabe ressaltar que se verificou uma evidente busca pelo consumo e compartilhamento de experiências extraordinárias em detrimento de bens materiais. Consciente ou inconscientemente, os sujeitos conferem aos bens materiais um maior aspecto de futilidade e superficialidade. 0 receio de que essa imagem seja tomada por terceiros como um reflexo de si instiga-os a expor, especialmente, as experiências vividas. A felicidade proveniente do compartilhamento de experiências é maior que aquela advinda de bens, principalmente, quando estas são vividas de forma conjunta. Do mesmo modo, vivências conferem uma maior sensação de self do que bens materiais.

Com isso, a felicidade presente nesse contexto orienta-se em sentidos distintos. Como reforçam os relatos, essa sensação pôde ser percebida não apenas após, mas até mesmo antes do ato da publicação. Não obstante, outro sentimento circunda o exercício proveniente dessa ferramenta virtual: a ansiedade. 0 chamado agradável desconforto surge como uma confluência entre esses dois aspectos distintos. Por conseguinte, os amigos/seguidores do Facebook, através das métricas (curtidas, comentários e compartilhamentos), reforçam ou reduzem essas sensações preliminares à publicação, assim como também influenciam significativamente o processo do consumo/reconsumo. 0 reconsumo pode ser visto como o resultado objetivo das inúmeras variáveis subjetivas que o antecedem. Esse desejo de reconsumo não necessariamente se orienta para a mesma experiência vivida, mas eventualmente para outra que esteja dentro de um padrão semelhante àquele capaz de gerar o impacto da repercussão inicial que foi positiva.

A partir da reflexão sobre os resultados alcançados, portanto, é notória a presença de algumas implicações teóricas, especialmente no que concerne ao âmbito mais subjetivo dos relatos. Destaca-se que, mesmo de maneira velada em discursos com tom de indiferença, há um notável desejo pela busca de prestígio, status, reconhecimento e autoestima. A exposição da vida em rede social e a interação que 
advém dessa dinâmica reforçam as relações sociais, conferindo uma maior sensação de não ser um indivíduo excluído ou afastado daquilo que se entende como padrão. Isto posto, o movimento entre vivenciar uma experiência e sentir-se disposto a compartilhá-la é dinâmico, não podendo ser conferida a ele uma única direção, mas orientações diversas e complexas, haja vista as intersubjetividades associadas a cada indivíduo. Não são somente as experiências estimulam a vontade de postar, mas a própria vontade de postar também impulsiona vivências.

Além do incremento às teorias que refletem sobre redes sociais e questões sociopsicológicas, este estudo também contribui com as teorias do comportamento do consumidor, uma vez que elucida aspectos outrora não investigados, como o ato do reconsumo em um contexto tão específico. Acrescentam-se, portanto, inferências a esse campo de estudo quando declara que reconsumir não é o ato último, mas está presente em um processo cíclico e permanente na dinâmica das mídias. É sob a égide desse processo que o indivíduo constrói suas relações ao passo que é constituído por elas, ansiando por felicidade em um eterno retorno à criatividade pessoal e à obediência aos padrões do grupo. Por fim, no que se refere, , às contribuições gerenciais, este trabalho fornece tacitamente diretrizes às marcas que desejam entender melhor o público para desenvolver seu gerenciamento de marketing, de produto, de serviço e/ou de campanhas publicitárias.

Como limitação do estudo, cabe ressaltar que, nas entrevistas, os usuários conduziram a navegação pelos seus perfis, expondo e esclarecendo as imagens postadas, comentários de amigos e demais elementos presentes em suas redes sociais. Dessa forma, os elementos presentes nos perfis foram interpretados pela perspectiva dos próprios entrevistados, os quais se caracterizam como fonte de informação primária dos achados da pesquisa. Todavia, conforme as recomendações da técnica de autodriving, sugere-se, como indicações de pesquisas futuras, o uso mais contundente de fotos, vídeos e demais aspectos visuais presentes nas redes sociais. Além disso, também é sugerido que uma pesquisa semelhante seja aplicada em outras redes sociais, especialmente o Instagram, objetivando-se, assim, investigar de que forma as particularidades das redes sociais afetam o consumo.

\section{Referências}

Barasch, A., Diehl, K., \& Zauberman, G. (2018). How the Intention to Share Can Undermine Enjoyment: Photo-Taking Goals and Evaluation of Experiences. Journal of Consumer Research, 44, 1220-1237.

Bhattacharjee, A., \& Mogilner, C. (2014). Happiness from Ordinary and Extraordinary Experiences. Journal of Consumer Research, 41(1), 1-17.

Becker, L., \& Jaakkola, E. (2020). Customer experience: fundamental premises and implications for research. Journal of the Academy of Marketing Science, 48, 630-648.

Belk, R. (2013). Extended Self in a Digital World. Journal of Consumer Research, 40(3), 477-500.

Belk, R., Ger, G., \& Askegaard, S. (2003). The fire of desire: a multisited inquiry into consumer passion. Journal of Consumer Research, 30(3), 326-351.

Braun, V., \& Clarke, V. (2006). Using thematic analysis in psychology. Qualitative research in psychology, 3(2), 77-101.

Braun, V., \& Clarke, V. (2017). Evaluating and reviewing TA research: a checklist for editors and reviewers. Auckland: The University of Auckland.

Bronner, F., \& Hoog, R. (2018). Conspicuous consumption and the rising importance of experiential purchases. International Journal of Market Research, 60(1), 88-103.

Bryman, A. (2008). Social research methods. Oxford: Oxford University Press.

Campbell, C. (1987). The romantic ethic and the spirit of modern consumerism. London: Blackwell.

Caprariello, P., \& Reis, H. (2012). To do, to have, or to share: The value of experiences over material possessions depends on the involvement of others. Advances in Consumer Research, 58, 550-551.

Carter, T., \& Gilovich, T. (2012). I am what I do, not what I have: The differential centrality of experiential and material purchases to the self. Journal of Personality and Social Psychology, 102(6), 1304-1317.

Carter, T., \& Gilovich, T. (2010). The Relative relativity of material and experiential purchases. Journal of Personality and Social Psychology, 98(1), 146-159.

Caselani, C. (2004). 0 custo da felicidade. GV Executivo, 3(1), 17-21.

Duan, J., \& Dholakia, R. (2018). How purchase type influences consumption-related posting behavior on social media: the moderating role of materialism. Journal of Internet Commerce, 17(1), 64-80.

Ellison, N., \& Boyd, D. (2013). Sociality Through Social Network Site. The Oxford Handbook of Internet 
Studies.

Fortis, J. (2015). The use of social media and its impacts on consumer behaviour: the context of holiday travel. Tese de Doutorado. Bounemouth University.

Frijda, N. (1986). The emotions. New York: Cambridge Univerty Press.

Gilovich, T., \& Gallo, I. (2020). Consumers' pursuit of material and experiential purchases: a review. Society for Consumer Psychology, 3, 20-33.

Gilovich, T., Kumar, A., \& Jampol, L. (2014). A wonderful life: experiential consumption and the pursuit of happiness. Journal of Consumer Psychology, 1-14.

Izard, C. (1971). The face of emotion. New York: Appleton-Century-Crofts.

Keiningham, T., Aksoy, L., Bruce, H. L., Cadet, F., Clennell, N., Hodgkinson, I. R., \& Kearney, T. (2020). Customer experience driven business model innovation. Journal of Business, 116, 432-440.

Jain, V., Belk, R. W., Ambika, A., \& Pathak-Shelat, M. (2020). Narratives selves in the digital world: An empirical investigation. Journal of Consumer Research, 1-13. Disponível em: $<$ https://doi.org/10.1002/cb.1869>

Krueger, R. (1998). Developing question for focus groups. Thousand Oaks, CA: Sage Publications.

Moore, S. (2014). Material Words: How Sharing Material and Experiential Purchases with Others Influences Self-Esteem. Advances in Consumer Research, 42.

Morgan, D. (1996). Focus Group. Annual Review of Sociology, 22(1).

Nicolao, L., Irwin, J., \& Goodman, J. (2009). Happiness for sale: Do experiential purchases make consumers happier than material purchases? Journal of Consumer Research, 36, 188-198.

Pereira, C., Siciliano, T., \& Rocha, E. (2015). "Consumo de experiência" e "experiência de consumo": uma discussão conceitual. LOGOS 43, Dossiê: Cotidiano e Experiência, 22(2), 6-17.

Perez, C. (2004). A comunicação da completude: a busca do objeto do desejo. Revista Mackenzie Educação, Arte e História da Cultura, 3(3), 109-116.

Pugh, J. (2010). A Qualitative Study of the Facebook Social Network: the desire to influence, associate, and construct a representative and ideal identity. Tese de Doutorado. California State University.

Reis, H., Smith, S. M., Carmichael, C. L., \& Caprariello, P. A. (2010). Are You Happy for Me? How Sharing Positive Events with Others Provides Personal and Interpersonal Benefits. Journal of Personality and Social Psychology, 99(2), 311-329.

Russell, C., \& Levy, S. (2012). The Temporal and Focal Dynamics of Volitional Reconsumption: A Phenomenological Investigation of Repeated Hedonic Experiences. Journal of Consumer Research, 39(2), 341-359.

Sibilia, P. (2015). 0 universo doméstico na era da extimidade. Nas artes, nas mídias e na internet. Revista ECO Prós, 18(1), 133-147.

Statista (2019). Global social networks ranked by number of users. Disponível em: <https://www.statista.com/statistics/272014/global-social-networks-ranked-by-number-ofusers/>. acesso em: 29/12/2019

Souza, L. (2019). Pesquisa com análise qualitativa de dados: conhecendo a Análise Temática. Arquivos Brasileiros de Psicologia, 71(2), 51-67.

Tomkins, S. (1984). Affect theory. In: Scherer, K. R \& Ekman, P. Approaches to emotion, Hillsdale, NJ: Erlbaum, 163-195.

Torres, P., Pereira, R., \& Santos, J. Em busca da felicidade: uma pesquisa sobre o bem-estar no consumo. In: Encontro da Anpad, 36., 2012, Rio de Janeiro. Anais... Rio de Janeiro: Enanpad, 2012, 1-16.

Van Boven, L., Campbell, M., \& Gilovich, T. (2010). Stigmatizing materialism: On stereotypes and impressions of materialistic and experiential pursuits. Personality and Social Psychology Bulletin, 36(4), 551563.

Van Boven, L., \& Gilovich, T. (2003). To do or to have? That is the question. Journal of Personality and Social Psychology, 85(6), 1193-1202.

Zhang, M., Li, Y., Gu, R., \& Luo, C. (2020). What type purchase of do you prefer to share on social networking sites: experiential or material? Journal of Retailing and Consumer Services, 58. 